\title{
Fenomenologi Sejarah Nuswantara
}

\author{
Herman Sinung Janutama ${ }^{1}$
}

\begin{abstract}
Abstrak
Tulisan ini mencoba mengemukakan mengenai hakikat kebudayaan Nuswantara dalam kaitannya dengan Islam sebagai rahmatan lil ngalamin. Upaya te9rsebut dilakukan dengan menggunakan beberapa macam pendekatan: pendekatan historis, semiotik, dan feminis;sehingga dapat menemukan fakta baru yang sebelumnya belum pernah mengemuka. Pendekatan historis memperhatikan literatur-literatur berbagai bangsa yang terindikasi pernah melakukan interaksi dengan Nuswantara seperti bangsa Semit (dalam hal ini Arab), Cina, dan Asian Selatan. Pendekatan tersebut berhasil menunjukkan adanya keterpengaruhan budaya-budaya lokal di beberapa wilayah di Nuswantara oleh budaya bangsabangsa asing itu yang dibagi ke dalam tiga pola: Pola Aceh-Sumatera (PAS) yang didominasi budaya Arab, Pola Sulawesi- Maluku (PSM) yang didominasi Arab-Cina, dan Pola Pulau Jawa (PPJ) yang menyatukan budaya Arab, Cina, dan Asia Selatan. Pendekatan Semiotik menggali simbol-simbol yang muncul dari interaksi antara bangsa tersebut sehinga ditemukan fakta bahwa simbolsimbol yang ada seperti Sanskerta dan Cina merupakan simbol transmisi sistem petanda Islam. Pendekatan feminisme mengupas berbagai macam fenomena dalam kebudayaan Nuswantara dari sudut feminim- maskulin. Pendekatan ini berhasil mengukuhkan bahwa Islam sebagai rahmatan lil ngalamin terjewantahkan dalam jiwa masyarakat Nuswantara yang memuliakan olah-rasa sebagai ekslporasi kenyataan feminitasnya.
\end{abstract}

Kata kunci : Islam sebagai rahmatan lil ngalamin, semiotik, feminis

\begin{abstract}
This paper tries to present the cultural fact of Nuswantara in relation to Islam as rahmatan lil ngalamin.This effort is done by using several kinds of approaches: historical approach, semiotic, and feminist; so that it can find new facts that had previously not been shown.The historical approach notice the literatures of many races which had a interaction with Nuswantara such as Semitic race (in this case Arabic race), Chinese, and South Asian.The results showed the presence of various local cultures influenced by foreign nations culture that is divided into three patterns: Pattern Aceh-Sumatra (PAS), which is dominated by Arab culture, patterns of Sulawesi-Maluku (PSM), which is dominated by ArabChinese, and Patterns Java (RPM) that combines these culture: Arabic, Chinese, and South Asia. Semiotic approach excavates symbols emerge from the interaction between the races which discovers the fact that symbols of Sanskrit and Chinese are symbols of Islam transmission system. Feminism approach analyzes a wide range of phenomena which is showing in Nuswantara cultur on feminine-masculine view. This approach works to strengthen that Islam as rahmatan lil ngalamin shows in Nuswantara people that honor the soul-felt as a exploration of their feminities.
\end{abstract}

Key Words: Nuswantara, Islam as rahmatan lil ngalamin, semiotic, feminism

\footnotetext{
${ }^{1}$ Institute of Philosopy Falsafatuna Jakarta
} 


\section{A. Pendahuluan}

Meninjau, mengunjungi, menyusuri, dan membaca situs-situs sebagai teks di Nuswantara ini, seperti sebuah suluk atau sebuah perjalanan ruhani. Perjalanan ruhani yang merupakan sebuah akt. Atau sebuah tindakan intelek untuk ngudi wikan sangkan paran. Artinya, menyelami pengetahuan-pengetahuan elementer mengenai hakikat atau asal muasal manusia Nuswantara. Aktus ngudi ini meliputi dua wilayah ekplorasi. Pertama, ngudi wikan sangkan paraning dumadi ${ }^{2}$ dan kedua, wikan sangkan paraning manungsa ${ }^{3}$.

Aktus demikian merupakan konsekuensi fenomenologis dari faktisitas manusia dalam mengada di dunia. Dunia yang telah diwahyukan mengada di hadapan kesadaran, merupakan sebuah dunia yang dialami, digeluti, diselami, dan dihayati. Inilah yang disebut sebagai lebenswelt dalam Fenomenologi. Sebuah dunia yang terkonstitusi dalam kesadaran manusia Nuswantara. Dengan dunia yang terkonstitusi demikian itu, memaknai manusia Nuswantara menjadi mungkin. Aktus intelek ini juga menyangkut fakta berikutnya, yakni bagaimana-sayamengada di dunia. "Saya" dalam kalimat tersebut bermakna manusia Nuswantara. Diskusi fenomenologis ini secara langsung berkaitan dengan eksistensi saya-manusia-Nuswantara di dunia. Eksistensi dalam bahasa Perancis adalah existo yang berarti to stand dalam bahasa Inggris. Sehingga menemukan sebuah pijakan atau standpoint merupakan sebuah amanat eksistensial. Pijakan eksistensial tersebut menjadi syarat bagi

2 Eksplorasi pengetahuan asali menyangkut keseluruhan wujud atau Ada. Lih. Ciptoprawiro, Abdullah, dr., Filsafat Jawa, PN Balai Pustaka, Jakarta, Media Wiyata, Semarang, Cet. 2, 1992.

3 Eksplorasi pengetahuan asali tentang "apabagaimana-ke mana" hidup dan kehidupan manusia. kesadaran manusia Nuswantara, agar mampu melakukan positioning dalam meng-hadapi seluruh pergulatan dan interaksinya dengan dunia.

Di jaman modern-global seperti sekarang ini, standpoint menjadi sebuah syarat eksistensial, sehingga mengalami yang global menjadi mungkin dan bermakna. Semua ini agar faktisitas sayamanusia-Nuswantara, mengIndonesia, Jawa-muslim- mampu mengonstitusikan semesta modern-global ini dalam keseluruhan struktur kesadaran mengada saya. Dengan kata lain, tidak menjadi saya yang berkesadaran semu. Yang senantiasa di-implant-kan oleh globalisme. Tidak menjadi saya-yangberpura-pura menjadi orang barat. Lidah Jawa menyatakan hal ini sebagai kamilondonen. Tidak juga menjadi sayayang-berpura-pura menjadi orang Arab atau Timur Tengah. Lidah Jawa menyatakan hal ini sebagai kamiaraben. Dalam istilah politik globalnya; tidak menjadi obama dan tidak pula menjadi osama.

Menjadi kamilondonen maupun kamiaraben artinya selalu menjadi bukansaya. Selalu menjadi bukan diri sendiri mengambang tanpa pijakan, atau yang disebut sebagai floating. Artinya, selalu mengambang atau terapung-apung, sehingga rentan terombang-ambing oleh akselerasi perubahan global yang melibas segala bentuk identitas. Modernisme sebagai orde global atau grand-narration terus menerus berkecenderungan memasivkan seluruh sub-orde atau subsub-narrations. Kenyataan ini merupakan efek dari will to power ${ }^{4}$ dari mainstream yang sudah tidak lagi rasional sebagaimana konsep awal dari semangat

\footnotetext{
4 Kehendak untuk berkuasa adalah terminology Nietzsche. Manusia cenderung ingin berkuasa. Dan kecenderungan ini sudah bukan aktifitas rasionalitas. Ia di luar rasionalitas, karena bersumber dari kehendak, bukan bersumber dari pengetahuan.
} 
modernisme. Masivikasi ini di sisi lain juga diperlukan oleh modernisme/grandnarration sebagai upaya melestarikan diri.

Floating atau terombang-ambing dalam arus jaman, merupakan wujud kegagalan dalam mengonstitusi dunia. Hal ini juga mengakibatkan kebutaan fenomenologis. Artinya, gagal melakukan positioning mengakibatkan hilangnya standpoint. Dalam artikulasi fenomenologi bisa dikatakan demikian di bawah ini. Das Ich mengalami amnesia sangkan paran, ia terjangkiti reduksi ekstrim epistemology. Ini adalah sebuah $d$ warfing, pencebolan. Fakta kemanusiaan das Ich yang seharusnya khalifatullah fil ardy tercebolkan menjadi semata sebagai sumber daya dan atau segmen pasar. Fakta kemusliman das Ich yang seharusnya rahmatan lil 'alamin tercebolkan menjadi regulasi ritual. Kemuliaan akhlak dan keluhuran ruhani tercebolkan menjadi adat dan pamali yang tribalistik. $* * *$

\section{B. Pembahasan}

\section{Eksplorasi Historis: Filsafat dan Gagasan Teoritik}

Standpoint dimaksud salah satunya adalah bagaimana memahami keseluruhan fakta lokalitas saya, baik secara filosofis, historis, maupun idealis. Dengan demikian membaca kekayaan budaya Nuswantara Hadiningrat (darussalam) menjadi sebuah aktus penting dan signifikan.

Membaca basis budaya Nuswantara berarti membaca basis budaya Indonesia. Namun pembacaan ini tidak mungkin dilakukan hanya dengan eksplorasieksplorasi internal. Sekalipun syarat batas geografis ini penting untuk kemudahan dalam analisis. Meninjau yang lebih luas, yakni konteks globalnya, atau horizone jamannya, ternyata memberikan makna pembacaan tersendiri. Relasi-relasi keterpengaruhan budaya Nuswantara dengan budaya global -dengan demikianpenting untuk dicermati.

Setiap budaya adalah merupakan konstruk jamannya. Maka penelitianpenelitian globalistik menyangkut $\mathrm{co}$ influences budaya Nuswantara dengan budaya-budaya dunia lainnya adalah sangat penting.

Amanat eksistensial dalam upaya eksplorasi konstitusi dunia, berkaitan langsung dengan eksistensi fenomenologi saya. Yakni berpijak pada fakta ke-sayaan saya, atau das Ichlichkeit. Dalam konteks budaya, saya secara erleben -apa adanya- terdeterminasi oleh faktisitas geografis: orang Nuswantara, mengIndonesia, dan Jawa-Muslim. Ini adalah takdir eksistensial saya. Determinandeterminan bagi cogito pra-refleksi folly/keculunan- maupun kesadaran atau cogito reflektif, das Ego. Karenanya ia menjadi fakta paling elementer dari das Ichlichkeit. Akibatnya harus dari sinilah insight bermula. Titik pijakan paling mungkin bagi sebuah worldview atau weltanschauung.

Secara

sosial-budaya, Nuswantara/Indonesia adalah sebuah kompleks yang mayoritas masyarakatnya adalah muslim. Fakta ini harus ditinjau terlebih dahulu secara obyektif-rasional, bukan subyektif-emosional. Dengan demikian era-era di atas harus dikomparasikan dengan periodisasi eraera pranata jaman di atmosfir kultur das Ichlichkeit. Dengan demikian relasi antar budaya menjadi mungkin dilakukan. Dengan komparasi konstitusi historis di atas, maka mengamati pergerakan konstitusi-konstitusi interbudaya menjadi mungkin. Secara semiotika/ semiologika, dengan komparasi ini dimungkinkan mengamati gerakan struktur petanda Islam sebagai grand-narration ke dalam dan di dalam budaya-budaya dan strukturstruktur penanda sub-sub narasinya.

Struktur tanda (petanda dan penanda) Islam sebagai grand-narration/ konstitusi 
dominanditransmisikan/ dikomunikasikan kepada seluruh struktur-struktur tanda (petanda dan penanda) yang menjadi $s u b$ sub narasinya/ sub-sub konstitusinya. Dengan demikian gerakan-gerakan konstitusi weltanschauung berikut operasi-operasi konversi struktur penandanya menjadi visible.

\section{Komparasi Tiga Area Budaya}

Secara geografis, eksplorasi ini mencakup 3 Area Budaya besar yakni Area Budaya Semitik (AB1), Area Budaya China (AB2), dan Area Budaya Asia Selatan atau Nuswantara (AB3). Di mana:

1. AB1 atau budaya semitik memiliki struktur simbol Yahudi-Arab. Dalam focus penelitian ini karena menyangkut Imperium Muslim dunia maka struktur symbol Arab Timur Tengah dipandang sebagai struktur primer. Sementara struktur simbol Yahudi/Ibrani menjadi wacana penjelasan sekunder.

2. AB2 atau budaya China memiliki struktur symbol yang mencakup luasan area hingga ke Jepang, Korea, Mongolia, serta Asia Tengah.

3. AB3 atau budaya Sanskerta memiliki cakupan area seluas Asia Selatan atau Nuswantara.

Terdapat relasi-relasi antar area budaya atau co-influences di sepanjang era Imperium Islam. Relasi-relaso tersebut sebagaimana di bawah ini.

Relasi I: $\quad \mathrm{AB} 1 \rightarrow \mathrm{AB} 2$.

Sejak tahun $617 \mathrm{M}^{5}$, atau awal abad 7, koinfluensi budaya ini merupakan konsekuensi dari terhamparnya Jalur Sutra Darat. Secara semiotik relasi ini mensyaratkan terdapatnya konversi

${ }^{5}$ Kumpulan Foto Kehidupan Muslim di China, di cetak di Republik Rakjat Tiongkok, Peking 1955. $\underline{\text { struktur symbol dari Arab Timur Tengah }}$ $\rightarrow$ China.

Relasi II: $\mathrm{AB} 1 \rightarrow \mathrm{AB} 3$.

Sejak tahun yang sama, yang merupakan konsekuensi dari terhamparnya Jalur Sutra Laut. Penetrasi ini terutama melalui Nuswantara Barat, sekitar AcehSumatera, Malaka, dan Jawa. Secara semiotik relasi ini mensyaratkan terdapatnya konversi struktur symbol dari Arab Timur Tengah $\rightarrow$ Sanskerta. Nuswantara termasuk dalam budaya berbasis struktur symbol Sanskerta.

Relasi III: AB2 $\rightarrow$ AB3.

Dua area budaya ini berbasis Jalur Sutra Laut, dan terutama melalui Nuswantara Timur, sekitar kerajaan-kerajaan Islam di Sulawesi, Maluku, Kalimantan, Nusa Tenggara, dan Jawa. Secara semiotik relasi ini mensyaratkan terdapatnya konversi struktur symbol China $\rightarrow$ Sanskerta.

Relasi-relasi ini membentuk SEGITIGA BESAR dengan AB3 di titik ujung selatannya. Posisi antara AB3 ini sangat mungkin menjadi penyebab numenklatur area ini disebut sebagai Nuswantara yang artinya (negeri) kepulauan antara. Yakni antara AB1 $\rightarrow$ AB2, dari Jalur Sutra Laut. Akibat dari relasi di atas, maka secara internal di Nuswantara, terdapat tiga pola pergerakan penyebaran Islam yang membentuk SEGITIGA KECIL ${ }^{6}$ dengan Pulau Jawa di titik ujung selatan:

1. Pola Aceh-Sumatera (PAS).

Relasi-relasi budaya dalam pola ini yang dominan adalah model budaya AB1 atau Arab Timur Tengah.

2. Pola Sulawesi-Maluku (PSM).

\footnotetext{
${ }^{6}$ Dr. Taufik Abdullah menyebut hal ini sebagai Tiga Pola Islamisasi Indonesia.
} 
Relasi-relasi budaya dalam pola ini yang dominan adalah model budaya AB2 atau Arab China.

\section{Pola Pulau Jawa (PPJ).}

Relasi-relasi budaya dalam pola ini yang dominan adalah model budaya komplwks dan akumulatif. Di mana struktur budaya Nuswantara AB3 harus berkoinfluensi baik dengan struktur-struktur budaya Arab Timur Tengah AB1, maupun struktur-struktur budaya China AB2.

Budaya-budaya pembentuk SEGITIGA KECIL dan sekitarnya ini pada era praIslam disebut budaya Indochina dengan dengan struktur symbol sanskerta-china. Setelah masa Islam masuk, terbentuk budaya Semit-China atau Arabo-China Muslim (Ta Chiek). Namun struktur simbolnya tetap mempertahankan Sanskerta. Di kemudian hari, struktur symbol sanskerta ini kemudian berkembang menjadi Kawi Jinarwa atau Jawa Kawi (era Majapahit), serta Jawa atau Jawa Klasik (era Mataram) dan Jawa kontemporer.

Dari pola-pola relasional Diagram Tripranata di atas diperoleh persamaan:

\section{$\mathbf{P P J}=\mathbf{A B} 1+\mathrm{AB} 2+\mathrm{AB3}$}

Arti persamaan ini adalah sebagai berikut:

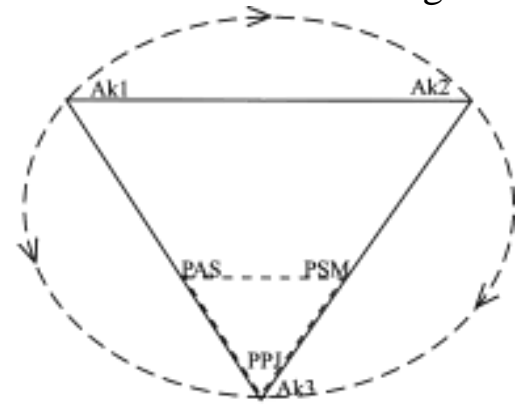

Diagram Tripranata:

Segitiga Konversi Tiga Area Budaya

1. Pola Pulau Jawa (PPJ) merupakan budaya muslim representasi akumulatif dari keseluruhan system simbol Imperium Muslim baik dari $\mathrm{AB} 1, \mathrm{AB} 2$, dan AB3.

2. PPJ secara umum merupakan konversi sistem simbol $\mathrm{AB} 1 \rightarrow \mathrm{AB} 3 \quad$ (Arab Timur Tengah $\rightarrow$ Sanskerta).

3. PPJ juga merupakan konversi sistem simbol $\mathrm{AB} 1+\mathrm{AB} 2 \rightarrow \mathrm{AK} 3 \quad$ atau Muslim-China $\quad$ (Ta-Chiek) $\rightarrow$ Sanskerta.

4. PPJ makna-makna budayanya dengan demikian dapat dijelaskan dengan mendekode sistem konversi AB1PAS $\rightarrow$ PPJ dan AB2-PSM $\rightarrow$ PPJ.

5. Dan sebaliknya, PPJ juga dapat digunakan untuk menjelaskan gejalagejala sosial budaya di AB1-PAS dan AB2-PSM.

6. Dengan demikian PPJ cukup representatif sebagai subyek penelitian gejala sosial budaya muslim baik secara global maupun lokal. Di mana lokalitas-globalitas budaya muslim memiliki relasi-relasi eksplanatif.

7. Relasi PPJ $\longleftrightarrow \rightarrow$ AB1-PAS adalah saling menjelaskan.

8. Relasi PPJ $\longleftrightarrow$ AB2-PSM juga saling menjelaskan.

9. Relasi AB1-PAS $\leftarrow \rightarrow \mathrm{AB} 2-\mathrm{PSM}$ dan $\mathrm{PAS} \leftarrow \rightarrow \mathrm{PSM}$, serta $\mathrm{AB} 1 \leftarrow \rightarrow \mathrm{AB} 2$, ketiganya juga dapat digunakan sebagai penjelasan sekunder bagi gejala-gejala sosial budaya di PPJ. $* * *$

\section{3}

\section{Tesis-tesis Terkait}

1. Roger Graudy menyatakan bahwa pasca fajar Islam abad ke $6 \mathrm{M}$, terjadi pertumbuhan kuil, masjid, candi, dan rumah-rumah ibadah lainnya di seluruh dunia secara signifikan yang belum pernah terjadi dalam sejarah manusia sebelumnya ${ }^{7}$. Artinya, bahwa

\footnotetext{
${ }^{7}$ Dr. Roger Graudy, The Balance-Sheet of Western Philosophy of this Century. Terjemah dalam
} 
sistem konsep dan makna Islam membawa spirit ruhani yang menginspirasi seluruh sistem spiritual yang telah ada di dunia. Termasuk di dalamnya adalah sistem spiritual berbasis Sanskerta di Asia Selatan atau Nuswantara/ Indonesia, dan di China.

2. Oracle Mpu Prapanca dalam Negarakertagama "Ilang Sirna Kertaning Bhumi" yang merujuk pada candra-sengkala 1400 Saka atau 1478 M. Oracle ini sekaligus merupakan ekstrapolasi bagi keruntuhan Imperium Islam Spanyol yang ditandai dengan runtuhnya Granada tahun 1492 M. Fakta historis ini dengan demikian menapis dugaan sebelumnya, bahwa orakel tersebut dinisbatkan kepada kemungkinan runtuhnya Majapahit era Brawijaya V. Namun dugaan ini tak terbukti, mengingat Majapahit pasca orakel ini masih terus berdiri hingga Brawijaya XI atau XIII.

3. Pusat Studi Sunda menyatakan, bahwa: "Sunda adalah Islam, dan Islam adalah Sunda"8.

4. Sabda Sinuwun Hamengkubuwana IX, bahwa: "Wong Jawa sing ora Islam kuwi dudu wong Jawa". Artinya bahwa orang Jawa yang tidak menganut agama Islam itu sama saja dengan bukan orang Jawa ${ }^{9}$.

bahasa Indonesia diterbitkan oleh Penerbit Risalah Bandung, Cet-1, Sep 1986.

${ }^{8}$ Dr. H. Edi S. Ekadjati, Ketua Dewan Pengurus Pusat Studi Sunda, Bandung,Jawa Barat, dalam Workshop Pengembangan Pendidikan Agama Perspektif Kultural. Diselenggarakan oleh Lembaga Penelitian UIN Jakarta, bekerjasama dengan Puslitbang Pendidikan Agama dan Keagamaan Balitbang Agama dan Diklat Keagamaan DEPAG RI. Ruang Sidang Utama UIN Jakarta. Tanggal 28 Oktober 2004.

9 Sabda ini beredar di kalangan masyarakat Ngayogya-karta, dan sudah menjadi rahasia umum di sana. Bahkan salah seorang sumber kami mengatakan bahwa para bangsawan yang
5. Peter L. Berger menulis,"...Islam mempunyai kemiripan dekat dengan Yudaisme, dengan perbedaan jelas bahwa Islam berhasil dalam menerapkan struktur-struktur konservatifnya bukan saja di dalam suatu subkultur yang terpisah, tetapi juga atas suatu kemaharajaannya yang mahaluas secara geografis." 10 Tesis ini menunjukkan sebuah fakta Imperium Islam sebagai Grandnarration atau orde-global atau ordemainstream dunia yang meliputi kawasan yang sangat luas (lihat uraian mengenai AK1, AK2, dan AK3). Satu-satunya agama yang pernah menjadi grand-narration dunia. Secara kronologis Islam menjadi orde dunia pertama bagi dunia global setelah 10 ribu tahun sejarah manusia di masa sebelumnya. Kolonialisme di samping visi gold-gospel-nya, juga bertujuan menggantikan grandnarration dunia dari Islam ke Western/modern. Hal ini di tandai dengan visi glory-nya yang berhasil menggantikan orde global Islam setelah kurun waktu 1000 tahun (mulai abad $6 \mathrm{M}$ - hingga abad $16 \mathrm{M}$ ). Sebagai perbandingan, semenjak aufklarung hingga saat ini, western/ modernitas menjadi orde global dunia, baru selama 400 tahun atau empat abad.

6. Jakob Sumardjo menulis,"Sejarah Islam di Indonesia harus ditinjau kembali. Buku-buku sejarah kita umumnya menyebut berdirinya kerajaan Islam pertama di Pasai pada akhir abad ke-13 M. Islam menurut Prof. Dr. Wan Hussein Azmi, dari Universitas Kebangsaan Malaysia, yang diutarakan tahun 1963, telah mulai di Sumatera (Melayu). Bahkan ketika Nabi Muhammad SAW masih

sulih agama dari Islam dilepas gelar
kebangsawanannya.
${ }^{10}$ Berger, Peter L., p. 148


hidup, yakni tahun $631 \mathrm{M}$, atau abad 7 M, atau abad 9 H... Hal ini masuk akal karena tahun $650 \mathrm{M}$ di Sumatera -menurut berita tua Cina- telah berdiri kerajaan Ta Shi yang menjalin hubungan diplomatik dengan Kerajaan Cina (Dinasti Han, pen.). Hubungan ini berlangsung sampai tahun 655 M. dikatakan bahwa kerajaan Islam Ta Shi berjarak 5 hari pelayaran dari Choppo, di seberang selat Malaka. Rupanya orang-orang China menyebut nama Ta Shi dari Ta Jik. Kata Tajik sendiri merupakan sebutan orang Persia kepada orang Arab muslim (Kabilah Taii). Maka kerajaan Tajik berarti kerajaan muslim (dengan unsure-unsur Arab di dalamnya). Inilah hasil dakwah pedagang dan pelayar Yaman, kurang lebih 20 tahun ke belakang. Kerajaan Islam pertama di Indonesia ini, kemudian menjadi bagian dari kerajaan Perlek, dan bernama Ta Jihan (catatan Cina). Dakwah itu bukan hanya terjadi di sekitar selat Malak, tetapi juga di Cina Selatan, Kanton dan pulau Hainan, di mana banyak pemukim pedagang Arab dan Parsi, bahkan juga di Champa. Kehadiran orang Arab dan Parsii ini telah dilakukan jauh sebelum jaman Islam, karena mereka berniaga sutera dengan Cina. Di samping itu mereka juga membeli kapur barus dari kepulauan Barus di pantai barat Sumatera. Kapur barus penting untuk ramuan mummi di Mesir. Tidak mengherankan apabila Barus juga termasuk wilayah Islam pertama di Indonesia sejaman dengan Ta Jik. Kemasyhuran Barus masih tersisa pada abad ke $16 \mathrm{M}$, ketika nama Hamzah Fansuri (Barus) dikenal sebagai ahli tasawuf Melayu."

\footnotetext{
${ }^{11}$ Jakob Sumardjo, Arkeologi Budaya Indonesia, Pelacakan Hemeneutis-Historis terhadap Artefak-artefak Kebudayaan Indonesia, Penerbit Qalam, Cet. I, Nopember 2002, hal. 54, 55.
}

Laporan Jakob Sumardjo ini sekaligus meruntuhkan asumsi bahwa terdapat periodisasi agama dalam sejarah Indonesia, yakani era Hindu, era Budha, dan era Islam. Atau era HinduBudha dan era Islam.

7. Di halaman yang sama Jakob melanjutkan, bahwa: "kebudayaan Islam berkembang sejaman dengan kebudayaan Hindu-Budha di Indonesia. Bedanya, kebudayaan Islam berkembang di lingkungan Melayu, dan kebudayaan HinduBudha di pulau Jawa". Tesis ini sekaligus menyatakan dua hal: pertama, latar belakang geografis dan konteks budaya Asia Selatan sebagaimana di paparkan Jakob di point 6, memberikan konsekuensi transmisi petanda Islam terus merasuk ke Jawa. Kedua, asas co-influences Jawa dengan budaya sekitar meniscayakan terjadinya konversi sistem symbol Islam ke dalam sistem symbol sanskerta, yakni sistem symbol yang lazim digunakan HinduBudha. Dengan kata lain, petnda Islam dalam kebudayaan Jawa ditransmisikan dalam symbol-simbol sanskerta/Hindu-Budha.

8. Chamamah menulis, bahwa: " nama sayidah Fatimah dalam kultur Islam di Jawa dikonversi menjadi Dewi Partimah atau Dewi Sri." 12

\section{4 \\ Metodologi: Pendekatan Semiotik}

1. Konstitusi dunia, konsep dan makna hidup Islam (sebagai struktur petanda) dan sistem bahasa Arab (sebagai struktur penanda), telah terdistribusikan sejak era awal mula Islam, ke seluruh peradaban dunia melalui jalur-jalur transportasi purba

\footnotetext{
${ }^{12}$ De Graaf, pada saat penulisan buku ini buku tersebut tidak berhasil ditemukan.
} 
yakni Jalur Sutra Laut dan Jalur Sutra Darat $^{13}$. Maka setelah struktur petanda Islam membentuk struktur penanda Semitik/Arab (lisanan arabiyan), lalu system tanda tersebut terkonversi ke dalam struktur penanda China dan Sankerta (Asia Selatan/ Nuswantara/ Indonesia).

2. Konversi ke dalam system tanda China berakhir di era Dinasti Ming, yakni dengan digulingkannya Dinasti tersebut sekitar 1644 M. Selanjutnya dilanjutkan oleh Dinasti Qing dari bangsa Manchuria (Mansuriyah, Mongol) yang juga runtuh di pertengahan abad 20 oleh rejim Komunisme.

3. Konversi ke dalam system tanda Sanskerta di Asia Selatan terus bertahan hingga sekarang, terutama di wilayah Indonesia. Di wilayah ini bahasa sanskerta terderivasi menjadi Bahasa Kawi. Selanjutnya, terutama di wilayah Pulau Jawa menjadi bahasa Jawa Kuna, bahasa Sunda Kuna. Kedua struktur penanda ini selanjutnya terderivasi menjadi bahasa Jawa serta Sunda Kontemporer.

4. Sekalipun telah mengalami kolonialisasi selama 350 tahun namun struktur-struktur tersebut tetap bertahan, fakta yang membuktikan hal ini adalah bertahannya dominasi kuantitas muslim di Indonesia, yakni sekitar $80 \%$.

5. Fakta ini sekaligus membuktikan bahwa struktur penanda Sanskerta menjadi struktur penanda paling komprehensif bagi operasi konversi dari struktur penanda Arab Timur Tengah (lisanan arabiyan). Dengan

13 -, Perkembangan Pengaruh Islam di Indonesia, Bahan Pelatihan Terintegrasi Berbasis Kompetensi Guru SMP, Pendidikan Kewarganegaraan dan Pengetahuan Sosial PS15, Depdiknas, Dirjen Pendidikan Dasar dan Menengah, Dirjen Pendidikan Lanjutan Pertama, 2004. bahasa lain, struktur penanda Sanskerta (berarti juga derivatderivatnya, yakni Jawa/Sunda dan bahasa-bahasa lainnya di seluruh Nuswantara) merupakan struktur penanda terbaik -bagi struktur petanda Islam- setelah bahasa Arab (lihat struktur tulisan beraksara Arab Pegon, misalnya). Atau lisaanan a'jamiyyan.

6. Secara genealogis, struktur petanda Islam -yang memuat ajaran, gagasan, konsep, pemahaman, pandangan hidup, adat-istiadat, ideology, teologi, dll- melestarikan diri dalam struktur penanda Sanskerta berikut seluruh derivasi bahasanya. Bahkan semenjak awal mula kemunculannya.

7. Roland Barthes menulis,'Tanda tidak hanya menjadi obyek dari pengetahuan tertentu, tetapi juga obyek dari sebuah visi, hampir sama dengan visi yang terdapat di dalam Ranah Gaib karya Cicero -Somnium Scipionis- atau berkaitan dengan representasi molekular yang digunakan oleh ahli-ahli kimia. Seorang semiolog MELIHAT dan MEMPERHATIKAN tanda bergerak lincah di medan pertandaan. Ia menyebutkan macam-macamnya, bekas-bekas konfigurasinya: bagi dia tanda adalah ide yang bisa diindra." 14

8. Secara semiotik, system tanda Islam melalui relasi komunikasi tertransmisikan ke struktur-struktur symbol/penanda China (AB2) dan Sanskerta (AB3).

9. Terjadi relasi konversi system tanda/symbol $\mathrm{AB} 1 \rightarrow \mathrm{AB} 2$ dan $\mathrm{AB} 1 \rightarrow \mathrm{AB} 3$ pada era Imperium Islam sejak akhir abad $6 \mathrm{M}$.

10. $\mathrm{AB} 1 \rightarrow \mathrm{AB} 2$ berarti system tanda Islam ditransmisikan kepada system

14 Roland Barthes dalam Spivak, Membaca Pemikiran Jacques Derrida, Sebuah Pengantar, Ar-Ruzz, Yogyakarta, Cet. 1, Mar 2003, p,113. 
tanda China, yang sebelumnya, di era pra-Imperium Muslim terutama digunakan sebagai system tanda Budhisme, Taoisme, Konfusianisme, Shinto, dll.

11. AB1 $\rightarrow \mathrm{AB} 3$ berarti system tanda Islam ditransmisikan kepada system tanda Sanskerta, yang sebelumnya, di era pra-Imperium Muslim terutama digunakan sebagai system tanda Hindu-Budhisme.

12. Maka semenjak akhir abad $6 \mathrm{M}$ baik struktur symbol Sanskerta maupun China menjadi struktur penanda (system symbol, bahasa) bagi transmisi system petanda (ajaran) Islam. Dengan lain perkataan, terjadi konversi struktur penanda dari Arab Timur Tengah ke struktur penanda Sanskerta dan China semenjak akhir abad ke $6 \mathrm{M}$.

13. Di Nuswantara, sejak akhir abad ke 6 $M$, atau setidaknya sejak awal abad ke $7 \mathrm{M}$, seluruh struktur penanda Sanskerta menjadi system symbol dari struktur petanda Islam. Dengan lain perkataan, sejak era ini, seluruh struktur penanda Sanskerta dapat dibaca dengan struktur petanda Islam.

14. Secara arkeologis, struktur penanda Sanskerta tertera dalam "teks" berupa situs-situs arkeologi baik berupa candi, kitab kuno, dan makam-makam kuno, serta bentuk-bentuk lainnya.

15. Secara antropologis, dapat ditemukan pada tradisi baik dalam struktur lisan maupun struktur mitologi. Di samping itu hampir keseluruhan kerajaan kuno di Nuswantara berhubungan langsung dengan genetika yang bersumber pada Nabi Muhammad SAW, Sayidina Ali dan Siti Fatimah putri Rasulullah SAW. Artinya, seluruh Nusantara dapat dihubungkan secara genetika dengan system kekerabatan Nabi Muhammad SAW.
Bertahannya keseluruhan system tanda Islam di Nuswantara/Indonesia menunjukkan beberapa gejala:

1. System tanda di Nuswantara/Indonesia adalah system tanda Islam.

2. Struktur petanda Islam melestarikan dirinya dalam struktur penanda Sanskerta.

3. Artinya juga melestarikan dirinya dalam struktur penanda Kawi.

4. Artinya juga melestarikan dirinya dalam struktur penanda Jawa Klasik dan kontemporer.

Konversi-konversi sistem bahasa dan simbol interarea di atas menjadi penting untuk dicermati. Dengan demikian penelitian ini menjadikan hal tersebut sebagai titik fokusnya. Maka dalam penelitian ini relasi-relasi komunikasi interarea juga menjadi hal yang penting, karena "..komunikasi, yang pada dasarnya berarti transmisi yang terjadi akibat pelepasan identitas obyek yang jadi petanda, berupa makna atau konsep, dari satu subyek kepada subyek lain, pada prinsipnya terpisah dari proses pemahaman dan proses pertandaan"15. Artinya, struktur petanda (Islam) yang memuat konsep dan makna (Islam), dapat ditemukan jejaknya dalam struktur pemahaman (struktur adat, pandangan hidup, dll) masyarakatnya. Dan dapat ditemukan dalam struktur penanda berupa struktur tanda/symbol (sanskerta) sebagai representasinya. $* * *$

\section{Metode Eksplorasi}

\section{Periodisasi}

Pada dasarnya penelitian adalah "pembacaan" keseluruhan situs sebagai

\footnotetext{
15 Jacques Derrida, dalam Gayatri Chakravorty Spivak, Membaca Pemikiran Jacques Derrida, Sebuah Pengantar, Ar-Ruzz, Yogyakarta, cet 1, Mar 2003, p,113.
} 
"teks" dari mulai ornamen, arca, relief, hingga atmosfir sosio-kulturalnya. Untuk kemudahan pelaksanaan penelitian maka dilakukan periodisasi atas "teks-teks" tersebut.

1. Periode I: yakni era pra-Majapahit hingga Majapahit. Umumnya situssitus di periode ini berupa candicandi.

2. Periode II: yakni era Majapahit hingga era Kolonial. Umumnya situssitusnya berupa makam-makam dan penanda-penanda kuno.

\section{Genealogi}

Pelacakan makna dapat juga diperoleh dari silsilah genetika tokoh-tokoh muslim. Silsilah ini diperoleh dari empat sumber:

1. Silsilah Para Raja dan bangsawan.

2. Silsilah Para Habaib.

3. Silsilah Para Kyahi.

4. Silsilah Tarekat.

\section{Numenklatur}

Numenklatur atau toponimi adalah pelacakan makna melalui tata nama, baik nama seseorang, daerah, masa/jaman, dll. Hal ini mungkin dilakukan disebabkan oleh tradisi yang selalu menghubungkan nama-nama dengan makna-makna simbolik tertentu.

\section{Pembacaan Simbol}

Simbol-simbol yang terdapat pada situs adalah system tanda bermakna. Mereka dapat terdekoding makna-maknanya. Hal ini mungkin dilakukan melalui dua cara:

1. Pembacaan arkeologis, melalui cocomparation dengan symbol-simbol yang terdapat pada situs lainnya yang sejenis.

2. Menggunakan metode Suhrawardian, dengan komunikasi "makna yang mendahului kata/tanda". ${ }^{16}$

\footnotetext{
16 Aksioma ke III dalam doktrin epistemology $\mathrm{Al}$ Isyraq Suhrawardi.
}

\section{Metode}

Survey/kunjungan/ziarah, interview, dokumentasi, dan studi pustaka. ***

\section{Ekstrapolasi Ethno-Kosmogonis: Femininitas Islam-Jawa}

Segitiga samasisi area kultur di atas membentuk segitiga samasisi yang titik-runcingnya menghadap ke bawah. Sebuah segitiga yang terkait dengan karakter feminin, karakter wanita, demikian tulis Helena Blavatsky ${ }^{17}$. Sebaliknya, disebut sebagai segitiga maskulin. Secara diagramatik, kedua segitiga ini dapat dianalogikan dengan sifat-sifat prisma ketika mendispersikan berkas cahaya.

Seberkas cahaya polikrom-tunggal yang dilewatkan kepada sebuah prisma, secara alamiah akan teruraikan menjadi berkas-berkas cahaya monokrom warnawarni. Teruraikan di antaranya menjadi tujuh (7) berkas warna cahaya monokrom: me-ji-ku-hi-bi-ni-u. Yakni berkas cahaya merah, jingga, kuning, hijau, biru, nila, dan ungu. Gejala optik ini secara alamiah analog dengan gejala transmisi awal suatu budaya dan agama (baca: Islam) di awal masa fajarnya.

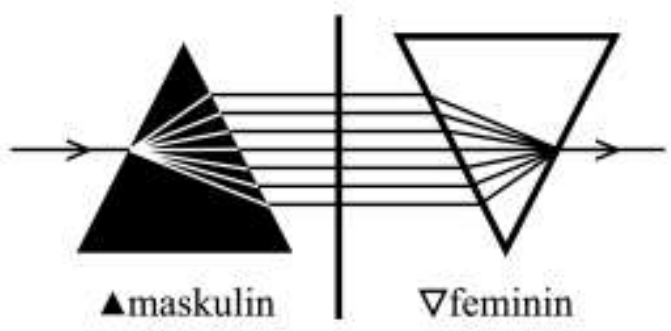

Diagram dispersi segitiga Maskulin-

Feminin

Berkas cahaya polikrom tunggal mengandung -dan sangat kaya dengananeka warna cahaya monokrom. Ia seperti sebuah ketunggalan dari kebhinekaan.

\footnotetext{
${ }^{17}$ Blavatsky, Secret Doctrines.
} 
Pluralitas yang tersingularkan. Dalam semesta budaya dan agama, ia mendiskripsikan universalitas tawhidullah dan fungsi rahmatan dari agama, khususnya Islam.

Di masa fajarnya Islam terdistribusi secara asri dan sederhana. Hal ini berbanding lurus dengan luasan determinasi ruang-waktu yang melingkupinya. Namun ketika hukum alam memaksanya meluas, ia harus tertransmisikan ke berbagai determinan ruang-waktu. Masing-masing determinan ruang-waktu memiliki minat serapan yang berbeda-beda. Maka cahaya tawhidullah dan fungsi rahmatan Islam terdispersikan sesuai lambda ${ }^{18}$ atau tipe budaya penerimanya. Yang singular terdispersi menjadi plural.

Seiring berjalannya waktu dan perkembangan keruangan budaya, dispersi cahaya Ilahi ini melahirkan pluralitas yang sesungguhnya tetap apresiatif. Namun entrophy ${ }^{19}$ positif yang terkandung dalam bentangan ruangwaktu, menyebabkan pluralitas ini kehilangan korelasi satu dengan lainnya. Hal ini menyebabkan setiap pluralis kehilangan kemampuannya untuk berintegrasi, setidaknya dalam konsep dan gagasan. Apalagi empirisme ekstrim memperlihatkan aneka ragam warna yang berbeda satu dengan lainnya. Akibatnya masing-masing pluralis terputus dari rantai causa verbanya ${ }^{20}$. Artinya ia kehilangan identitas awalnya. Sehingga masing-masing pluralis mengalami disorientasi.

Di samping itu, transmisi dan distribusi tawhidullah di era fajar Islam terdeterminasi oleh karakter jaman yang

18 Lambda adalah panjang gelombang cahaya. Analog dengan intensitas dan minat resapan penerima.

19 Salah satu konsekuensi dari Hukum Thermodinamika II: bahwa segala sesuatu akan mengalami kerusakan.

20 Hukum sebab akibat. maskulin. Yakni kehormatan yang diletakkan pada kekerasan dan kekuasaan $^{21}$ atau kamukten. Maskulinitas ini dalam tradisi Yunani dinisbatkan kepada dewa Crom, tradisi Romawi: dewa Mars. Suatu tradisi yang sangat bergantung kepada politik dan peperangan, tipu muslihat dan pedang. Dalam diagram di atas, gejala ini disimbolkan dengan segitiga maskulin.

Rahmatan lil ngalamin sebagai fungsi mundial Islam, tetap muncul ke permukaan sejarah. Namun ia lebih bersifat individual dan sporadis. Bukan merupakan sistem orde mainstream global. Ia lebih merupakan gerakan spiritual yang dimotori para sufi dan imam tarekat. Sementara terdapat kesenjangan signifikan antara mereka dengan sistem-sistem monarki muslim yang berkuasa. Hal ini berjalan hingga era keruntuhan peradaban muslim sejak kolonialisme awal abad $16 \mathrm{M}$.

Peradaban indah tersebut meninggalkan pecahan-pecahan parsialis yang berserakan. Berikut kebutaan mengintegrasikan dirinya dengan gagasan singularitas tawhidullah sebagaimana era fajarnya. Maka kolonialisme global lambat laun mulai menggeser posisi grand-narration imperium monarki muslim.

\section{Segitiga Feminin}

Secara diagramatik, inverse karakter dari segitiga maskulin adalah segitiga feminin. Fungsi segitiga feminin ini dalam diagram dispersi di atas, adalah "menuntun" berkas-berkas cahaya monokrom aneka warna kepada forma

\footnotetext{
21 Terutama semenjak era imperium kerajaankerajaan muslim bertahta. Yakni semenjak berakhirnya kepemimpinan imamat muslim dari Imam Ali bin Abi Thalib, Imam Hasan bin Ali bin Abi Thalin dan Imam Husein bin Ali bin Abi Thalib.
} 
integratifnya. Yang plural menemukan singularitasnya.

Relasi simbolik segitiga MaskulinFeminin menurut Corbin -yang merujuk kepada Ibn Arabi- adalah sbb:

The relationship between $r a b b$ and marbub, between lord and knight, light and colour, can be illustrated by two interpenetrating spheres or more clearly still, in the world of surfaces, by two interpenetrating triangles.

Relasi segitiga maskulin-feminin mencerminkan relasi dua dimensi: marbub-rabb, knight-lord, colour-light. Segitiga maskulin adalah segitiga profan. Ia adalah simbolisasi kenyataan kemanusiaan yang aneka warna dan penuh pertarungan. Sementara segitiga feminin adalah segitiga transenden. Simbolisasi dari kenyataan ilahiyah manusia yang pengasih, pemomong, dan cahaya cemerlang.

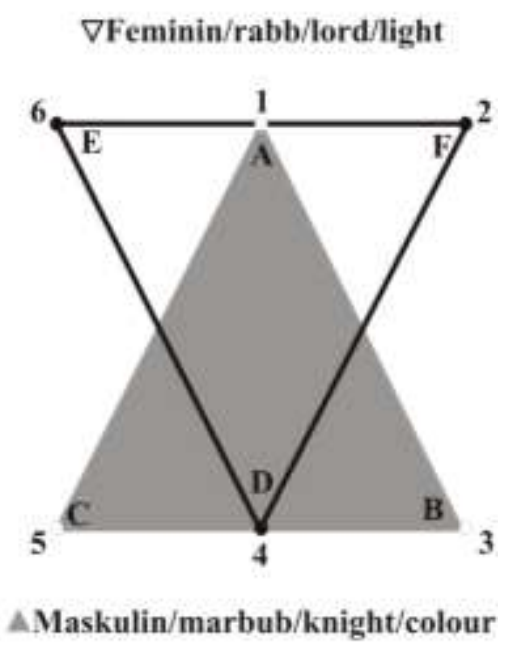

\section{Diagram Korelasi Segitiga Maskulin- Feminin}

Lebih jauh bisa dinyatakan bahwa untuk menuntun parsialitas-pluralis kembali menemukan integrasi singular-nya, memerlukan kerja mundial sistematik yang feminin. Artinya suatu kerja mundial yang berbasiskan kemuliaan ruhani, keluhuran akhlak dan budi pekerti, bersifat keibuan/feminin, kasih sayang, membimbing, momong, dll. Ringkasnya, ia adalah sistem kerja mundial yang hame-mangun karyenak tyasing sesami ${ }^{22}$. Sistem tindakan yang merahmati keseluruhan kemanusiaan, atau rahmatan lil ngalamin. Sistem demikian muncul dari manusia yang mengolah rasa, olahrasa. Manusia yang mengeksplor kenyataan feminitasnya ${ }^{23}$.

Sepanjang sejarah dunia, masyarakat manusia yang memuliakan olah-rasa adalah orang Jawa, atau Nuswantara. Dan dengan demikian refunction dari sistem rahmatan lil ngalamin dari Islam sebagaimana digagaskan pada era fajarnya- dapat dilakukan -jika dan hanya jika- merupakan sebuah sistem kasihsayang. Sistem ini tak lain adalah Islam bercorak Nuswantara atau Islam-Jawa.***

\section{Penutup}

1. Tesis dalam eksplorasi ini menjawab pertanyaan seorang Amerika yang tengah mencari pandangan hidup elementer bagi spiritualitas manusia. Ia bertanya kepada saya, "Mengapa dalam setiap kebudayaan di seluruh dunia, saya selalu menemukan Islam sebagai leitmotive-nya?" 4

2. Berdasarkan asas analogi-konversi, maka Sanskerta adalah penanda Islam, setidaknya semenjak abad 7 M. Maka seluruh sistem simbol

\footnotetext{
${ }^{22}$ Sesanti jumenengan Kangjeng Panembahan Senopati sebagai sultan Kerajaan Islam Mataram Hadiningrat.

${ }^{23} \mathrm{Nabi}$ Agung Muhammad SAW menjelaskan relasi feminitas dengan olah-rasa:"pada maskulinitas terdapat 9 rasio dan 1 rasa, sedangkan feminitas terdapat 9 rasa dan 1 rasio" 24 Percakapan Budaya dengan Charles Holand Taylor (North Caroline, USA), Lobby Hotel Melia Purosani, Yogyakarta, sekitar pertengahan tahun 2004. CHT telah mengembara ke Pakistan, India, Iran, Irak, Maroko, dll -kecuali Arab Saudi.
} 
Nuswantara/Indonesia adalah penanda Islam, sehingga struktur penanda Kawi juga Islam, dan struktur penanda Jawa, Sunda, dll, adalah juga struktur penanda Islam.

3. Islam yang rahmatan lil ngalamin tak lain adalah Islam bercorak

\section{Daftar Pustaka}

Ciptoprawiro, Abdullah, dr., Filsafat Jawa, PN Balai Pustaka, Jakarta, Media Wiyata, Semarang, Cet.2, 1992.

Kumpulan Foto Kehidupan Muslim di China, di cetak di Republik Rakjat Tiongkok, Peking 1955.

Dr. Roger Graudy, The Balance-Sheet of Western Philosophy of this Century. Terjemah dalam bahasa Indonesia diterbitkan oleh Penerbit Risalah Bandung, Cet-1, Sep 1986.

Jakob Sumardjo, Arkeologi Budaya Indonesia, Pelacakan HemeneutisHistoris terhadap Artefak-artefak Kebudayaan Indonesia, Penerbit Qalam, Cet. I, Nopember 2002, hal. 54, 55.

-, Perkembangan Pengaruh Islam di Indonesia , Bahan Pelatihan Terintegrasi Berbasis Kompetensi Guru SMP, Pendidikan Kewarganegaraan dan Pengetahuan Sosial PS-15, Depdiknas, Dirjen Pendidikan Dasar dan Menengah, Dirjen Pendidikan Lanjutan Pertama, 2004.

Roland Barthes dalam Spivak, Membaca Pemikiran Jacques Derrida, Sebuah Pengantar, Ar-Ruzz, Yogyakarta, Cet. 1, Mar 2003, p,113.

Jacques Derrida, dalam Gayatri Chakravorty Spivak, Membaca Pemikiran Jacques Derrida, Sebuah Pengantar, Ar-Ruzz, Yogyakarta, cet 1, Mar 2003, p,113.
Nuswantara, atau Islam-Nuswantara. Setidaknya corak keislaman seperti itulah yang diperlukan bagi kemanusiaan di seluruh dunia saat ini. Dunia yang carut-marut diterpa barbarisme modernitas global. *** 
